\title{
Nodular malignant melanoma in the nasolabial fold
}

\author{
Mehmet Eren Yuksel1', Funda Tamer ${ }^{2}$
}

\author{
${ }^{1}$ Department of General Surgery, Aksaray University School of Medicine, Aksaray, Turkey, ${ }^{2}$ Department of Dermatology, \\ Ufuk University School of Medicine, Ankara, Turkey
}

Corresponding author: Dr. Funda Tamer, E-mail: fundatmr@yahoo.com

Sir,

A 93-year-old Caucasian female presented with a hemorrhagic nodule in the right nasolabial sulcus. The patient stated that the lesion had been present for a year and it had increased in size gradually. The hemorrhagic nodule was asymptomatic except for occasional bleeding. Physical examination of the patient revealed an ulcerated and hyperpigmented nodule with a size of $2 \times 1 \times 1 \mathrm{~cm}$ in the right nasolabial fold (Figs. 1 and 2). There were also hyperpigmented papules and patches surrounding the hemorrhagic nodule. The lesion was removed surgically in order to reach a definitive diagnosis (Fig. 3). The histopathological examination of the specimen revealed nodular malignant melanoma with Breslow thickness of $5 \mathrm{~mm}$. Moreover, there was epidermal ulceration, intense pigmentation and slight lymphocytic infiltration. The patient was referred to medical oncology department for further treatment.

Malignant melanoma is classified as lentigo maligna, superficial spreading, nodular, and acral melanoma based on its growth pattern. 15-20\% of all melanoma cases are nodular melanoma. Predilection sites of nodular melanoma are head, neck and trunk and it is more common in men than women. Nevertheless, nodular melanoma clinically presents as a pink or hyperpigmented nodule with definitive borders. It may also ulcerate and bleed [1]. Nodular melanoma has only a vertical growth phase and it grows rapidly [2]. The lesion may appear within few months to two years and it can metastasize quickly [3]. Therefore, nodular melanoma has worse prognosis than any other subtypes of melanoma [2]. It has been suggested that differences between melanoma subtypes might be associated with the stem cells they originated. Nodular melanoma originates from dermal stem cells while the

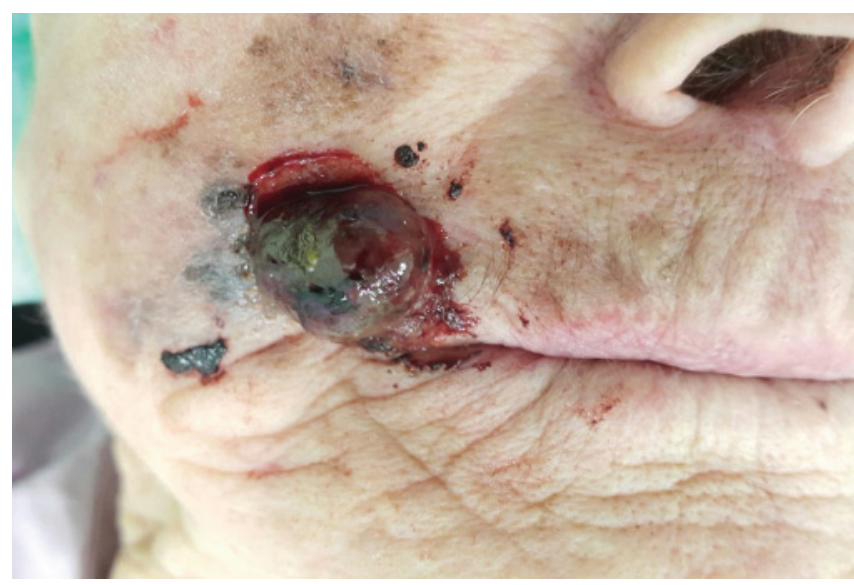

Figure 1: Hyperpigmented hemorrhagic nodule in the right nasolabial fold. The pathological evaluation of the specimen revealed a $2 \times 1 \times 1 \mathrm{~cm}$ nodular malignant melanoma.

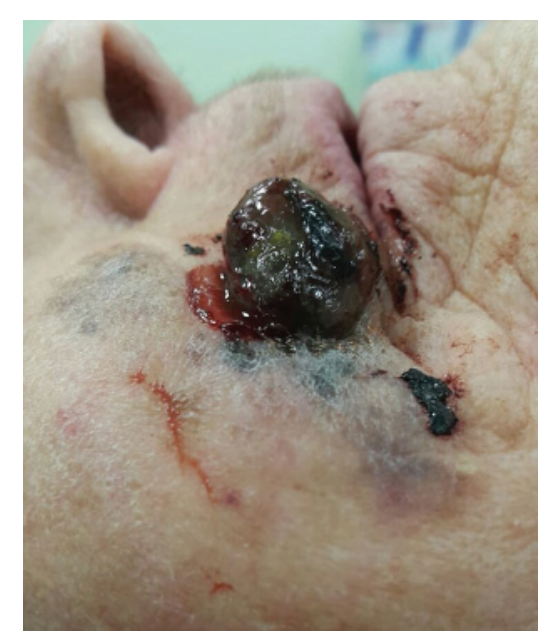

Figure 2: The lateral view of the nodular malignant melanoma lesion.

other subtypes originate from epidermal stem cells [2]. However, the most important independent prognostic factor of all types of melanoma is Breslow thickness. Five year survival rate for melanoma with Breslow depth less than $1 \mathrm{~mm}$ is $90-100 \%$. However, the survival rate

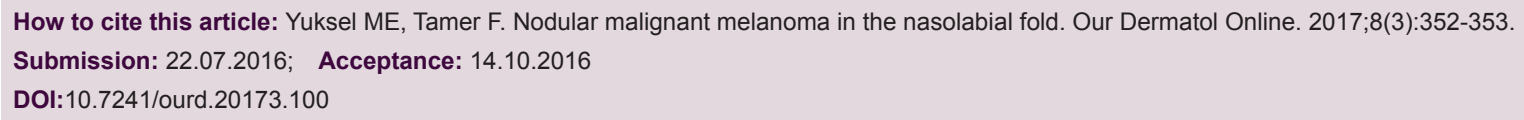




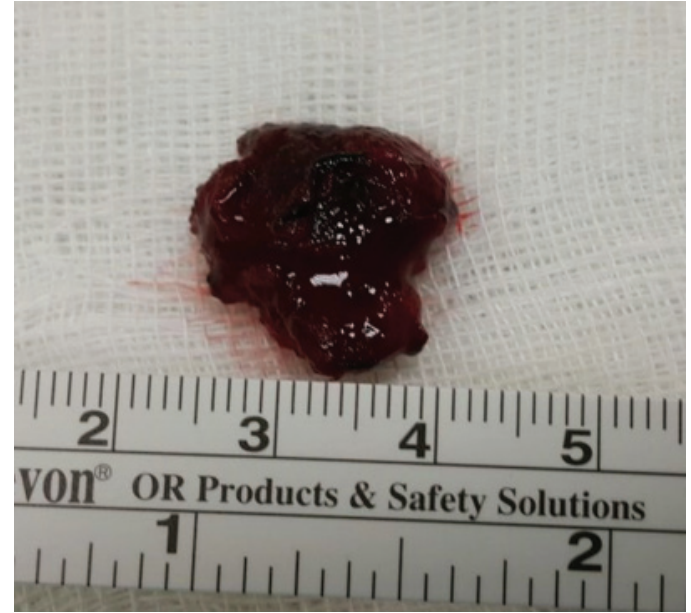

Figure 3: The specimen after surgical excision.

decreases to $50 \%$ when the Breslow depth is greater than $4 \mathrm{~mm}$. People with fair skin and multiple dysplastic nevi are more likely to develop nodular melanoma. Positive family history and ultraviolet exposure are other risk factors [3]. Moreover, Finet et al. reported a patient who developed nodular melanoma after 8 months of tocilizumab therapy because of severe rheumatoid arthritis [4]. Early detection of melanoma lesions is important to reduce mortality. Therefore, Moreau et al. evaluated 10475 patients with nodular melanoma and reported factors associated with early detection of the tumor. Moreau et al. revealed that divorced, seperated or never married people were more likely to have thick nodular melanoma compared with married individuals. Furthermore, living in areas with high dermatologist density or living in areas with high Papanicolaou test use and mammography use decreased the risk of having thick nodular melanoma. In addition, they reported that tumor thickness was not associated with socioeconomic environment [5].

The photograph of the lesion presented within this article is very demonstrative for advanced nodular malignant melanoma in the nasolabial fold. Bearing in the mind that early diagnosis is life saving, patients should be warned to seek medical attention in case of any rapidly growing skin lesions.

\section{REFERENCES}

1. Kibbi N, Kluger H, Choi JN. Melanoma: Clinical Presentations. Cancer Treat Res. 2016;167:107-29.

2. Kalkhoran S, Milne O, Zalaudek I, Puig S, Malvehy J, Kelly JW, et al. Historical, clinical, and dermoscopic characteristics of thin nodular melanoma. Arch Dermatol. 2010;146:311-8.

3. Erkurt MA, Aydogdu I, Kuku I, Kaya E, Basaran Y. Nodular melanoma presenting with rapid progression and widespread metastases: a case report. J Med Case Rep. 2009;3:50.

4. Finet A, Amini-Adle M, Balme B, Colson F, Thomas L. Nodular progression of lentigo malignant melanoma during a treatment with tocilizumab: cause or coincidence? Clin Rheumatol. 2013;32:277-80.

5. Moreau JF, Weinstock MA, Geller AC, Winger DG, Ferris LK. Individual and ecological factors associated with early detection of nodular melanoma in the United States. Melanoma Res. 2014;24:165-71.

Copyright by Mehmet Eren Yuksel, et al. This is an open access article distributed under the terms of the Creative Commons Attribution License, which permits unrestricted use, distribution, and reproduction in any medium, provided the original author and source are credited.

Source of Support: Nil, Conflict of Interest: None declared. 